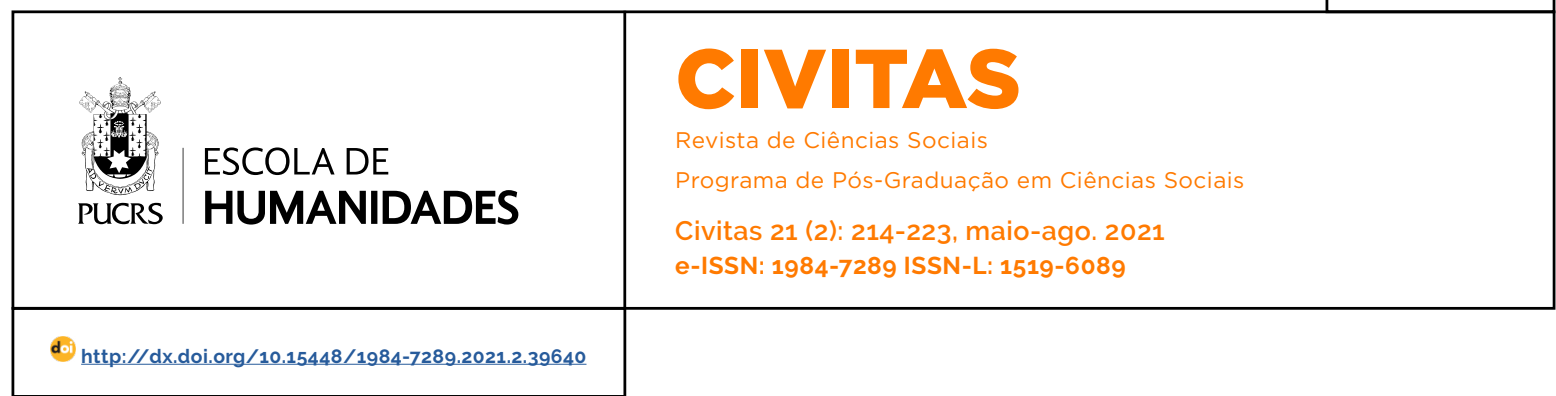

DOSSIÊ: DIGITALIZAÇÃO E DATAFICAÇÃO DA VIDA: PERVASIVIDADE, UBIQUIDADE E HIBRIDISMOS CONTEMPORÂNEOS

\title{
Os dados estão nos engolindo?
}

Are the data swallowing us?

¿Nos tragan los datos?

Lucia Santaella ${ }^{1}$

orcid.org/0000-0002-0681-6073

lbraga@pucsp.br

\section{Dora Kaufman ${ }^{1}$}

orcid.org/0000-0001-7060-4887

dkaufman@pucsp.br

Recebido: 27 nov. 2020

Aprovado: 13 abr. 2021

Publicado: 24 ago. 2021

\section{(c) (1)}

Artigo está licenciado sob forma de uma licença Creative Commons Atribuição 4.0 Internacional.
Resumo: Este artigo visa definir e colocar em discussão três conceitos e práticas interconectadas, mas, ao mesmo tempo, irredutiveis: big data, datificação e dataísmo. São conceitos recentes que se impuseram devido ao aumento vertiginoso de dados que correm a uma velocidade impar na internet. As discussões se desenvolvem para desembocar com mais ênfase no dataismo hoje criticado como uma nova forma de religião. São colocadas em evidência suas ambivalências, paradoxos e contradições, em especial o paradoxo do uso ininterrupto das redes e as novas contradições do capitalismo que são alimentadas por esse uso. A balança que oscila entre o desejo do usuário e os efeitos nefastos na lógica mais recente do capitalismo abre um abismo que este artigo coloca sob reflexão. Palavras-chave: Big data. Datificação. Dataísmo. Contradição. Capitalismo.

Resumen: Este artículo tiene como objetivo definir y discutir tres conceptos y prácticas interconectadas, pero, al mismo tiempo, irreductibles: big data, datificación y dataismo. Se trata de conceptos recientes que se han impuesto debido al vertiginoso aumento de datos que corren a una velocidad única en internet. Las discusiones se vienen desarrollando, poniendo más énfasis en el dataismo hoy criticado como una nueva forma de religión. Se destacan sus ambivalencias, paradojas y contradicciones, especialmente la paradoja del uso ininterrumpido de las redes y las nuevas contradicciones del capitalismo que se alimentan de este uso. El equilibrio que oscila entre el deseo del usuario y los efectos nocivos sobre la lógica más reciente del capitalismo abre un abismo que este artículo pone bajo reflexión. Palabras clave: Big data. Datificación. Dataismo. Contradicción. Capitalismo.

Abstract: This article aims to define and discuss three interconnected concepts and practices, but, at the same time, irreducible: big data, datification and dataism. These are recent concepts that have been imposed due to the vertiginous increase of data that run at a unique speed on the internet. Discussions are developed to lead to more emphasis on dataism today criticized as a new form of religion. Its ambivalences, paradoxes and contradictions are highlighted, especially the paradox of the uninterrupted use of networks and the new contradictions of capitalism that are fueled by this use. The balance that oscillates between the user's desire and the harmful effects on the most recent logic of capitalism opens an abyss that this article places under reflection.

Keywords: Big data. Datification. Dataism. Contradiction. Capitalism.

\section{Introdução}

Vivemos na era do big data. Disso não pode haver dúvida. Nenhuma novidade científica, tecnológica ou cultural cai do céu como um paraquedas. É sempre bom pensar nisso para evitar a preguiça do presentismo de um lado, e o preconceito mal-informado de outro. Big data caracteriza-se não apenas pelo volume, mas por uma rica mistura de tipos e formatos de 
dados, pela variedade e pela natureza sensivel, ao mesmo tempo que marca um desvio do processamento em lote tradicional, velocidade. Embora tenha se tornando, nos últimos anos, uma espécie de palavra de ordem, sua emergência é fruto de uma série de fatores que vieram se desenrolando a partir do advento da cultura do computador, que trouxe, entre muitos outros fatores, a crescente mudança de escala de processamento computacional e o agigantamento da circulação de informações na internet.

Sessenta anos atrás, os computadores digitais tornaram a informação legivel. Trinta anos atrás, a internet tornou-a acessivel. Vinte anos atrás, o primeiro motor de busca transformou-a em um único banco de dados. Agora as empresas Google e afins estão tratando esse corpus massivo como um laboratório da condição humana. Essas empresas são as filhas geradas pelos petabytes.

A expressão big data foi popularizada, em 2005, por Roger Mougalas do O'Reilly Media, um ano depois da divulgação do termo Web 2.0 por Tim O'Reilly. Em 2007, muitos autores alertavam para o fato de que as técnicas das entrevistas e de levantamento de exemplos estariam se tornando obsoletas frente à sem precedentes mudança de escala e de escopo dos dados. Em vista disso, tornou-se popular a expressão data analysis divide, cunhada pelo conhecido cientista e artista das mídias, Lev Manovich, ${ }^{2}$ para significar algo como o antes e o depois da análise de dados. Ainda sem utilizar a expressão big data, o diretor da revista Wired, Chris Anderson, ${ }^{3}$ em 2009, portanto, há onze anos, lançou um artigo de teor sensacional sob o seguinte título: "A era dos petabytes: porque mais não é apenas mais - mais é diferente. A chamada do artigo diz:

Sensores em todos os lugares. Arquivamento infinito. Nuvens de processadores. Nossa habilidade para capturar, armazenar e compreender quantidades massivas de dados está mudando a ciência, a medicina, os negócios e a tecno- logia. Na medida em que nossa coleção de fatos e figuras cresce, assim também cresce a oportunidade para encontrar respostas para questões fundamentais. ${ }^{3}$

Na escala petabyte, a informação exige uma abordagem totalmente diferente, que nos obriga a tomar a corrente de dados como algo que pode ser visualizado em sua totalidade. Obriga-nos a visualizar os dados matematicamente primeiro e estabelecer um contexto para mais tarde. Assim, quando confrontada com dados massivos, as tradicionais abordagens para a ciência - levantamento de hipótese, modelo e teste - está se tornando obsoleta. A nova disponibilidade de enormes quantidades de dados, juntamente com as ferramentas estatísticas para mastigar esses números, oferece toda uma nova maneira de compreender o mundo. Escrito há onze anos, naquele momento, o artigo soava extremamente polêmico não obstante a ciência já estivesse fazendo farto uso de analytics e visualização de dados. A radicalidade do texto lhe valeu críticas pela negação dos métodos qualitativos e, mais especialmente, pela despolitização dos fenômenos sociais nele implícita. Entretanto, a evolução do big data, de lá para cá, acaba por nos levar a constatar o caráter premonitório das perspectivas abertas pelo texto.

A partir de 2008, a frequência do big data, nas pesquisas e a suas aplicações nas mais diversas áreas das atividades humanas, tornou difícil cultivar dúvidas acerca do fato de que a era do big data havia chegado. Embora parecesse ser um campo exclusivo dos cientistas da computação, já que são eles os responsáveis pela criação de algoritmos para o processamento e tratamento dos dados, já eram muitas as áreas de conhecimento e prática - física, economia, matemática, ciência política, bioinformática, comunicação, marketing, sociologia, e outras - que reclamavam pelo acesso a uma quantidade gigantesca de informação que é produzida e que é indicativa

\footnotetext{
2 Manovich, Lev. 2008. Software takes command. Software studies initiative (blog), 20 nov. 2008. Acessado 30 mar. 2009. http://lab.softwarestudies.com/2008/11/softbook.html. Manovich, Lev. 2011. The promises and the challenges of big social data. Cultural analytics lab (blog), 28 abr. 2011 Acessado 10 jan. 2013. http://manovich.net/content/04-projects/067-trending-the-promises-and-the-challenges-0f-big-social-data/64-article.

3 Anderson, Chris. 2009. The Petabyte Age: because more isn't just more - more is different. Wired, 23 jun. 2009 . Acessado 05 abr. 2010. http://www.wired.com/science/discoveries/magazine/16-07/pb_intro.
} 
do que fazem as pessoas, de como andam as coisas, de todas as interações entre elas e dos processos resultantes. Assim, em 2015, a expressão big data já começava a correr de boca em boca, especialmente no mundo empresarial e organizacional. Infelizmente, no contexto acadêmico brasileiro, seu uso era incipiente. Mas, de poucos anos para cá, big data e ciência dos dados tornaram-se temas obrigatórios.

De fato, não só a pesquisa, mas quase todas as atividades garantidoras do andamento da vida social estão hoje imersas e dependentes de dados. Diversos grupos já se valem dos benefícios de se analisar sequências genéticas, interações nas midias sociais, relatórios de saúde, relatórios governamentais e outros traços digitais deixados pelas pessoas. Disso decorreu o surgimento de uma nova ciência, a ciência dos dados, mas junto com ela, compondo as ambivalência e paradoxos do mundo digital contemporâneo, surgiram críticas fulminantes.

\section{Big data}

Embora estejam emparelhados, big data, datificação e dataísmo não são sinônimos. Big data é neutramente definido como o agigantamento e desmesura crescente dos dados gerados, armazenados e disponibilizados pelos meios digitais no mundo contemporâneo. Em 2014, Barrachina e O'Driscoll apresentaram o estado da arte relativo ao crescimento dos dados que vale a pena retomar, pois nele constam previsões para o ano 2020. De acordo com os autores, as informações do mundo dobram a cada dois anos, de modo que, em 2020, estariamos na ordem de 4OZB (zetabytes). A previsão para 2025 é de um volume de dados de 175ZB, crescimento exponencial considerando que em 2010 foram produzidos "apenas" 2ZB. ${ }^{4}$ Desde 2014. esse aumento de dados passou a ser chamado de "tsunami de dados", impulsionado pela proliferação de midias sociais, juntamente com um aumento de dispositivos móveis e em rede (internet das coisas), finanças e varejo on-line, além de avanços no setor fisico e setores de ciências da vida.
Em 2014, o Twitter já processava aproximadamente 12 TB (terabytes) de dados por dia, enquanto o Facebook recebia mais de quinhentos milhões de curtidas diárias. Em 2020, o Google processa, em média, mais de 40.000 consultas de pesquisa a cada segundo, o que se traduz em mais de 3.5 bilhões de pesquisas por dia e 1,2 trilhão de pesquisas por ano. Segundo a IBM, a cada segundo, 300 horas de vídeo são carregadas no YouTube, 204 milhões de e-mails são enviados e 500.000 comentários são postados no Facebook. ${ }^{5}$ Para o Cisco Internet Business Solutions Group (IBSG), em 2020, já teríamos alcançado 50 bilhões de dispositivos conectados à internet e que 1,7 bilhão de novas informações seriam desenvolvidas por segundo por todos os habitantes do planeta.

Diante disso, não é à toa que os tradicionais sistemas e bancos de dados distribuidos, por estarem baseados em dados estruturados e exibirem escalabilidade limitada, cairam em desuso ao perderem a adequação para capturar, armazenar, gerenciar e analisar tal montante de dados. Um volume que, sob esse nome de big data, passou a requerer novas arquiteturas projetadas para escalabilidade, resiliência e processamento paralelo eficiente.

A astronomia e a genômica foram as ciências pioneiras no uso de grandes quantidades de dados, o que passou, então, a ser acompanhado por quase todos os campos de conhecimento. Ao adotar o big data, implicitamente, aceita-se trocar a causalidade e a exatidão pelas correlações que indicam, apenas, a probabilidade de um determinado fenômeno ocorrer. Migramos dos modelos estatísticos baseados em amostragens, relativamente pequenas, para modelos estatísticos baseados em conjuntos volumosos de dados, implicando mudança de natureza, ou de essência como preferem Viktor Mayer-Schonberger e Kenneth Cukier (2013).

Nessa medida, com o advento do big data, as técnicas estatísticas, desenvolvidas até recentemente para a maioria das aplicações, tornaram-se 
inaptas, sendo gradativamente substituidas pelos modelos estatísticos de inteligência artificial (IA). Particularmente a nova geração de técnicas de aprendizado de máquina, denominadas de Redes Neurais de Aprendizado Profundo (Deep Learning Neural Networks - DLNNs). Umas das grandes diferenças é a capacidade das DLNNs de lidar com grandes quantidades da variável "dimensionalidade" (milhões de pixels, por exemplo, no reconhecimento de imagem) com impacto positivo no grau de acurácia dos resultados.

Atualmente, a IA está automatizando decisões, processos e fluxos de trabalho e, com base no big data, prevendo eventos futuros com alto grau de assertividade. As DLNNs tornaram-se fator estratégico de processos decisórios em múltiplas tarefas em distintos setores da economia e da sociedade. Essas técnicas, contudo, têm limitações intrínsecas, uma delas é o fato de prever o futuro com base em dados do passado (inferências de tendências passadas) e, sempre bom lembrar, como todos os modelos estatísticos de probabilidade, seus resultados indicam apenas a probabilidade de algo acontecer e quando.

\section{Datificação \& dataísmo}

A datificação, por seu lado, apesar de estar umbilicalmente engatada a esse estado de coisas, designa a transformação em dados de todos os aspectos da vida em sociedade, colocando os eventos em um formato quantificável e permitindo analisar e compará-los, ou seja, transformar as atividades cotidianas em informação, essa percebida como nova forma de valor (Mayer-Schonberger e Cukier 2013). Por sua vez, o termo "dataísmo" foi utilizado pela primeira vez por David Brooks, do New York Times, em 2013. "Se me pedissem para descrever a filosofia emergente da atualidade, diria que é o Dado-ismo", ele dizia, ao argumentar que, "num mundo crescentemente complexo, confiar nos dados pode reduzir as distorções cognitivas e [...] iluminar padrões de comportamento que ainda não tínhamos observado".6 Em 2015. Steve Lohr, no seu livro Data-ism, refletiu sobre as transformações que o big data passou a operar na sociedade, utilizando o termo para descrever a grande revolução dos dados.

Assim, o dataísmo passou a se referir ao culto aos dados como fonte suprema de compreensão do mundo, visão originada entre tecnólogos do Vale do Silicio. É, portanto, muito mais uma filosofia, ou melhor, uma ideologia ou uma nova religião, adorada por alguns e abominada por outros, uma nova versão dos conflitos milenares entre fiéis e hereges, apenas que, agora, os templos foram substituidos pelas olimpicas forças do capitalismo de dados, capitalismo de vigilância ou neocolonialismo digital segundo o batismo dos críticos.

O frisson provocado pelo termo dataísmo veio com a publicação do livro Homo Deus, de Harari (2016), frisson potencializado pelas entrevistas concedidas pelo autor e por todo o zumbido de matérias apressadas e, muitas vezes, sensacionalistas que se seguiram à publicação desse best seller mundial. O alarido resultou, entre outras coisas, do fato de que Harari matou dois coelhos com uma única cajadada, ao colocar o dedo na ferida de duas noções sagradas e consagradas: a religião e o velho humanismo. Com isso, o significado originalmente neutro do termo dataísmo foi expandido para abrigar o que Harari ${ }^{7}$ chamou de ideologia emergente ou mesmo uma nova forma de religião, em que "o fluxo de informação" vem à tona como "valor supremo". À semelhança de qualquer religião, o dataísmo tem mandamentos práticos. Um seguidor dessa nova religião, o dataísta, deve querer "maximizar o fluxo de dados, interligando-se cada vez mais", pois acredita piamente na liberdade de informação e confia mais no big data e nos algoritmos de computador do que no conhecimento e sabedoria humanos.

Em uma entrevista concedida à Revista Wired, ${ }^{8}$

\footnotetext{
6rooks, David. 2013. The philosophy of data. The New York Times, 05 fev. 2013. Acessado 30 de out. 2020. https://www.nytimes com/2013/02/05/opinion/brooks-the-philosophy-of-data.html.

Harari, Yuval Noah. 2016. Homo sapiens is an obsolete algorithm. Wired, 08 set. 2016. Acessado 15 mai. 2019. https://www.wired. co.uk/article/yuval-noah-harari-dataism.

8 Solon, Olivia. 2017. Sorry, Y'all-humanity's nearing an upgrade to irrelevance. Wired, 25 mar. 2017. Acessado 15 mai. 2019. https://www. wired.com/2017/02/yuval-harari-tech-is-the-new-religion/.
} 
as declarações de Harari foram inquietantes, para dizer pouco. Além de uma ideologia e uma religião, o dataísmo é também um mercado emergente que não venera deuses nem homens, mas venera os dados. Harari afirma que, de uma perspectiva dataísta, toda a espécie humana tende a tornar-se menos importante, talvez irrelevante, na medida em que o significado é gerado pelo sistema externo de processamento de dados.

Assim concebida, a história humana como um processo de melhoria da eficiência desse sistema, pode ser compreendida por meio de quatro métodos básicos, a saber: a) aumento do número de processadores; b) aumento da variedade dos processadores; c) aumento do número de conexões entre processadores e d) aumento da liberdade de movimento ao longo das conexões existentes. ${ }^{9}$

Após explicitar cada um desses métodos, Hara$\mathrm{ri}^{8}$ conclui com a seguinte frase: "O homo sapiens é um algoritmo obsoleto. Afinal, qual a vantagem dos humanos sobre as galinhas?" Nem pessimista, nem cínica, nem alarmante, a afirmação é, sobretudo, acachapante, com o mérito de nos empurrar para a necessidade de repensar a ontologia do humano. Afinal, o que somos nós humanos, ou o que sobrou de nós, melhor, o que sobrou do que pensávamos que éramos, agora que nos tornamos praticantes da religião dos dados?

Infelizmente, a ideia do "humano" está ainda enredada no antropocentrismo, não obstante o humanismo tradicional não ser mais capaz de explicar as relações complexas entre o homem, os animais, o meio ambiente e a tecnologia. O conceito tradicional de "ser humano", abstraindo as demais relações, encontra-se hoje alargado pelo acoplamento com tecnologias, impossibilitando identificar os limites do que seja humano e não humano, inclusive identificar os limites do corpo diante dos dilemas da cognição expandida para além do corpo biológico.

Alguns autores (Frischmann e Selinger 2018; Zuboff 2019; O'Neal 2018) alertam sobre o comprometimento pelos sistemas inteligentes da capacidade humana mental e sua interação com o mundo exterior como agente social, ou seja, sobre os atributos humanos como livre-arbitrio e autonomia. Frischmann e Selinger (2018, 225) definem livre arbítrio como "a capacidade situada do agente de se engajar em um exercício reflexivo de autodeterminação sobre sua vontade (crenças, desejos, valores, gostos)"; e a autonomia é definida como "a ponte entre vontade e ação, o processo interno pelo qual os humanos criam suas intenções para agir". Contudo, a crescente adoção do big data, da análise preditiva e dos ambientes inteligentes desafia a ideia-chave do Iluminismo sobre a autonomia e livre-arbitrio e o fazem com total opacidade, o que poderá levar a uma "re-engenharia" dos humanos transformando-os em previsiveis e programáveis.

\section{Lamentações contra o dataismo}

Apesar dos indicadores que impelem a superação do antropocentrismo, não faltaram e continuam a não faltar reações em defesa do velho humanismo, justamente aquele que, desde o Renascimento, veio crescentemente a alimentar o individualismo, sede do egoísmo e da ilusão imaginária de um eu, senhor do seu pensamento e no livre arbítrio do seu destino. Segundo Harari, ${ }^{10}$ o humanismo cultivou a ideia de que as experiências ocorrem dentro de nós, e é dentro de nós que devemos encontrar o sentido de tudo que acontece, pois cabe a nós, a partir do nosso antropocentro, infundir o universo de significado. Entretanto, agora afogados em números, para lembrar essa célebre frase antecipatória no título do filme, de 1988, de Peter Greenway (Drowning by numbers), não faltam lembranças daquilo que o dataísmo leva embora de nós, ao levar de roldão antigos modos de buscar e encontrar informação:

Quando queriamos saber alguma informação para nos ajudar a decidir, recorríamos antigamente ao consultor, ao professor, ao chefe, ao vendedor, à enciclopédia ou até ao

\footnotetext{
Harari, Yuval Noah. 2016. Homo sapiens is an obsolete algorithm. Wired, o8 set. 2016. Acessado 15 mai. 2019. https://www.wired. co.uk/article/yuval-noah-harari-dataism.

10 Solon, Olivia. 2017. Sorry, Y'all-humanity's nearing an upgrade to irrelevance. Wired, 25 mar. 2017. Acessado 15 mai. 2019 . https://www wired.com/2017/02/yuval-harari-tech-is-the-new-religion/.
} 
padre da paróquia. Tínhamos como base de conhecimento as grandes religiões, como o Cristianismo, o Induísmo, o Budismo e o Islamismo, bem como as grandes teorias econômicas como o Capitalismo e o Marxismo. Mas muita coisa está mudando rapidamente. $O$ conhecimento sobre o bem e o mal, bem como a tomada de decisões no dia a dia, vêm agora, cada vez mais, com o apoio de alguma aplicação de software e menos do conhecimento adquirido pessoalmente ou, diretamente, de outras pessoas, livros ou instituições clássicas. Google, Facebook, Linkedin, Wikipedia ou até os sites de meteorologia e o Youtube começam a ser de maior confiança e rapidez do que os antigos métodos de consulta e análise. ${ }^{11}$

Apesar dessas evidências, continua a haver uma espécie de rebeldia contra a previsão de Harari muitíssimo repetida nas redes e, inclusive, pelo próprio, de que os algoritmos serão "hackers da humanidade" e nos conhecerão melhor do que nós mesmos. "Quando isso acontecer, a crença no individualismo entrará em colapso e a autoridade vai se transferir de indivíduos humanos para algoritmos em rede" (2016, 333).

Diante disso, Ferreira reclama que, desde os anos 1980, a utopia e o messianismo, sempre foram "a narrativa pela qual as corporações como Microsoft, Apple ou Oracle vendiam o futuro para os usuários".12 Hoje, elas evoluiram para uma estranha distopia "na qual autoabdicação humana e messianismo religioso se misturam. O que resulta numa espécie de tecno realismo amargo sobre um futuro inevitável onde nos tornamos dependentes da tecnologia. Dando continuidade a esse discurso, Ferreira (2017) afirma que

A fala de Harari faz parte de uma nova narrativa publicitária das corporações tecnológicas: projetar para o futuro distopias que sempre fascinaram a humanidade por toda a História: ver a si própria substituída por duplos tecnológicos como reflexos em espelhos, fotografias, frankensteins, golens, robôs, replicantes e, agora, aplicativos.

A maior parte das lamentações relativas ao dataísmo acabam tendo como atrator ou força gravitacional aquilo que é popularmente chamado de datificação do eu, ou seja, a conversão de aspectos de nossas vidas em dados computadorizados que, cada vez mais, encontram-se monitorados pelos algoritmos de IA. Isso quer dizer que tudo o que postamos nas redes, inclusive as buscas que fazemos, nossas fotografias, todas as espécies de postagens, curtidas, mensagens e afiliações, tornam-se todas elas parte do eu digital que nos permite navegar na internet e redes sociais, mas, ao mesmo tempo, nos expõe a hackers, roubo de identidades e superexposição no geral.

Sem descartar esses perigos iminentes, há que apontar para o paradoxo que se instala entre as pessoas não deixarem de incessantemente postar a si mesmas nas redes e o mal-estar social que esses novos duplos digitais também não cessam de provocar. Esse mal-estar não parece ser outra coisa senão uma versão agora bem mais incrementada do conto William Wilson, de Edgar Allan Poe (1985), conto que tematiza o Zeietgeist da invenção da fotografia, ou seja, o estranhamento perante os duplos do eu que conduziu os artistas e poetas à desconfortável consciência da alteridade psíquica do eu, quer dizer, o reconhecimento de que há um outro do eu capaz de provocar o efeito de Unheimlisch, o estranho familiar de si mesmo, questão que a psicanálise iria tematizar algumas décadas depois de Poe (Santaella 1985). No seu texto-comentário do conto O Homem da Areia, de Ernst. T. A. Hoffmann (2010), Freud (2019) desvendou a especificidade do mecanismo psíquico que faz emergir uma sensação ligada à angústia e ao horror e que é experimentada como algo ao mesmo tempo muito longe e muito perto de nós, muito estranho e muito familiar, muito inquietante e muito próximo.

Não é por acaso que os literatos produziram os seus textos problematizantes no tempo histórico do surgimento da fotografia. Na realidade, desde a invenção da fotografia, o ser humano passou a produzir duplos de si mesmo, algo que atingiu uma exponenciação com as câmeras digitais a ponto de levar a Fundação Oxford Dictionaries a

11 Costa, Carlos. 2018. Dataísmo, a religião do século XXI. ClO (blog), 01 ago. 2018. Acessado 10 de nov. 2019. https://cio.com.br/tendencias/dataismo-a-religiao-do-seculo-xxi/.

12 Ferreira, Wilson. 2017. O homem se tornará irrelevante diante de algoritmos e aplicativos? Jornal GGN, 03 mar. 2017. Acessado 10 nov. 2019. https://jornalggn.com.br/tecnologia/o-homem-se-tornara-irrelevante-diante-de-algoritmos-e-aplicativos/. 
escolher "Selfie" como a palavra do ano de 2013 (Santaella e Cara 2014). Hoje, segundo Kerckhove, o ser humano está incessantemente produzindo gêmeos digitais. A expressão "digital twins", no mundo empresarial, é definida como modelos de simulação de produtos, mas a ideia veste como uma luva as simulações do eu na vida digitalizada:

Imagine que em nosso smartphone vive um gêmeo digital, uma entidade feita de big data, que lhe dá a resposta mais precisa sobre seu destino, sua saúde, a próxima coisa que você tem que fazer, a única pessoa com quem você deve ou não se casar. Tudo isso se torna uma extensão fenomenal desde que o gêmeo digital cresceu e agora se chama Alexa (assistente da Amazon.com). E este também é um problema muito sério porque continuamos a pensar que ainda somos nós que tomamos as decisões. ${ }^{13}$

Essa ideia pode ser amplificada para além da Alexa e nos servir para definir todo o processo de criação e desenvolvimento contínuo de gêmeos digitais a partir dos rastros ininterruptos com que cada usuário vai alimentando as plataformas digitais que frequenta. Gêmeos que, segundo Harari, sabem muito mais de nós do que nós mesmos. Certamente, a proteção de dados pessoais é um valor humano inviolável. Isso não pode cegar, entretanto, para o fato de que, por trás da reivindicação de proteção, via de regra, oculta-se uma noção neocartesiana do eu, que é retroalimentada pelas próprias redes. A saber, ilusões imaginárias de um eu autônomo e unificado que se julga doloridamente ferido pelos gêmeos digitais produzidos por si mesmo. Tal paradoxo, entretanto, não está só, pois se faz acompanhar pelos temas relativos à datificação que passaram a ocupar o primeiro plano dos debates nos últimos anos.

\section{Novas acrobacias do capitalismo}

Quando o tema do capitalismo se vê qualificado sob o atributo de "novas formas", não se pode deixar de lembrar que o capitalismo, não obstante suas crises, tem dado guinadas que se assemelham a acrobacias. A última delas é a que brotou do big data e do dataísmo e que vem recebendo o nome de capitalismo de plataforma (Srnicek 2017), capitalismo de dados (Mayer-Schönberger e Ramge 2018), capitalismo de vigilância (Zuboff 2019) e, ainda, de capitalismo neocolonialista, ou melhor neocolonialismo de dados (Couldry e Mejias 2019).

Já em 2012, Fernanda Bruno chamava atenção para o fato de que nosso rastro digital é transformado em uma moeda valiosa para uma indústria extremamente complexa, que envolve plataformas proprietárias e o governo, mas também o mercado publicitário, a indústria da comunicação e informação e, por último, e com certeza não menos importante, as corretoras de dados.

Em 2020, o crescimento exponencial dos dados agregado aos resultados positivos da implementação do modelo empírico de aprendizado de máquina, a técnica de deep learning, gerou uma capacidade de prever eventos futuros com inédita assertividade. Sendo a capacidade preditiva um dos fundamentos de qualquer atividade econômica e social, essa técnica de IA está se disseminando aceleradamente, adotada no desempenho das mais diversas funções desde diagnósticos médicos até personalização da informação, da aprendizado, de concessão de crédito. Atualmente, é raro um setor de atividade que não a adote, no mínimo, como parceiro da inteligência especializada de um profissional humano. Nas atuais condições do debate, as teclas, que são repetidamente tocadas, dizem respeito às consequências da datificação para a privacidade, o controle, a vigilância, especialmente para o abalo das instituições modernas da sociedade e, sobretudo, para a crise das democracias ocidentais (Van Dijck 2017).

A tese central do livro Capitalismo de plataforma versa sobre a maneira como os dados são capturados, processados e monetizados por proprietários de plataformas como Facebook e Google. Embora muito crítico em relação a essas empresas, Srnicek (2017) oferece uma descrição realista de seus modelos de negócios, sem deixar de apontar para os seus desafios na medida que

13 Kerckhove, Derrick de. 2020. Domus, 05 fev. 2020. And then the digital assistant became our master. Acessado 12 out. 2020. https:// www.domusweb.it/en/news/2020/02/05/then-the-digital-assistant-became-our-master.html. 
os motores básicos do capitalismo forem postos em ação, forçando a busca por novas maneiras de crescer e aumentar os lucros.

Muito mais comentado do que a tese de Srnicek está sendo o livro de Zuboff, Capitalismo de vigilância (2019), que ganha fama crescente. Nele é exposta a natureza de um novo regime de acumulação do capital baseado na vigilância. Este tipo de capital é definido como uma "nova ordem econômica que reivindica a experiência humana como matéria-prima gratuita para práticas comerciais de extração, previsão e vendas" (Zuboff 2019, ix). Para ela, o que se tem aí é uma "mutação desonesta do capitalismo marcada por concentrações de riqueza, conhecimento e poder sem precedentes na história humana" (Zuboff 2019, ix). Trata-se, portanto, de uma forma de capitalismo que captura ações humanas tanto online quanto offline para facilitar a modificação e exploração comercial de comportamentos futuros. Para Zuboff (2019) os modelos preditivos de IA, originalmente concebidos para melhorar o desempenho e otimizar os processos, estão sendo utilizados para manipular os indivíduos, comprometendo a prerrogativa básica dos seres humano de pensar e decidir, ou seja, serem agentes.

Alinhado com essas preocupações, Stuart Russell (2019) argumenta que o desafio é garantir que os sistemas inteligentes não exerçam poder sobre os humanos. Os algoritmos de seleção de conteúdo nas mídias sociais, por exemplo, são projetados para maximizar a probabilidade de o usuário clicar nos itens desejados, parte desse objetivo é alcançado via mecanismos indutores de preferências: "Como qualquer entidade racional, o algoritmo aprende como modificar o estado de seu ambiente - neste caso, a mente do usuário - para maximizar sua própria recompensa" (Russsell 2019, 9).

Frischmann e Selinger (2018) advertem que os algoritmos de IA não são apenas instrumentos comerciais, mas possibilitam prever e interferir em nossa conduta em todas as esferas da vida social de maneira inédita. Para os autores, assim como os GPS estão subtraindo a prerrogativa de localização, os sistemas inteligentes vão substituir nossa percepção, intuição e empatia, determinando nosso comportamento. Para eles, aceitamos esses termos seduzidos pela promessa de "smart tools" para facilitar e melhorar nossas vidas.

Outra versão crítica das formas atuais do capitalismo, com bastante penetração na América Latina, foi desenvolvida por Nick Couldry e Ulisses Mejias, no livro The cost of connections (2019). Para os autores, uma nova forma de exploração colonial começa a ganhar corpo visivel na medida que o fascínio tecnológico decresce e aumentam as preocupações com as consequências sociais, políticas e econômicas da massificação das inovações na área da comunicação e informação. Embora, à primeira vista, pareça estranha a junção do digital com o colonialismo, os autores explicam que mega fortunas acumuladas por empresas que captam, arquivam, processam e vendem dados obtidos, sem custo, de usuários da internet. Surge com isso, uma nova modalidade de capitalismo alimentada não mais por bens materiais como minérios, petróleo e alimentos, mas pela comercialização de dados do quotidiano das pessoas. ${ }^{14}$

Em uma perspectiva ímpar, Byung-Chul Han (2017) contesta a conjugação do tema da transparência, viabilizada no big data, com o tema da liberdade de informação. Para o autor, está em curso a contraposição da "sociedade da negatividade" à "sociedade da positividade", com a eliminação da ambivalência e, consequentemente, da alteridade. A sociedade da transparência busca eliminar todas as relações assimétricas, gerando uma sociedade opaca e homogênea.

É significativo que o Facebook se negue coerentemente a introduzir um emotion de dislike button. A sociedade positiva evita todo e qualquer tipo de negatividade, pois esta paralisa a comunicação. Seu valor é medido apenas pela quantidade e velocidade de troca de informações, sendo que a massa de comunicação também eleva seu valor econômico e vereditos negativos a prejudicam. Com like surge uma comunicação conectiva muito mais rápida do que com o deslike (Han 2017, 24)

14 Castilho, Carlos. 2018.0 colonialismo de dados prepara a versão digital do capitalismo. Carlos Castilho Medium (blog), 27 out. 2018. Acessado 02 mar. 2020. https://ccastilho.medium.com/o-colonialismo-de-dados-prepara-a-vers\%C3\%A30-digital-do-capitalismo-cc78a0cgbe74. 
Essas ideias originais são, no mínimo, controversas. Parte da pressão atual sobre as grandes plataformas tecnológicas, particularmente o Facebook, sustenta-se no argumento oposto, de que a velocidade de disseminação dos conteúdos negativos, especialmente de ódio, é superior à velocidade de disseminação dos conteúdos positivos. A alegação para reformular, ou mesmo revogar, a Seção 230 da Lei de Decência das Comunicações/1996/EUA (Limiting Section 230 Immunity to Good Samaritans Act) - garantia de imunidade às plataformas de internet pelo conteúdo produzido por seus usuários - é justamente que as redes sociais têm interesse em conteúdos prejudiciais e/ou ilegais pela capacidade destes de gerar mais dados.

Han (2017) crê que vivemos um novo tipo de panóptico de Bentham, o panóptico digital que ele define como aperspectivístico por não ser mais vigiado por um centro, mas supervisionado por todos e de qualquer lugar, que ele denomina de "democratização da supervisão". Ademais, os presos do panóptico de Bentlam estavam cientes da vigilância constante e não podiam se comunicar entre si, ao passo que os usuários das redes digitais têm a ilusão de total liberdade e mantêm intensa intercomunicação. "Hoje, a supervisão não se dá como se admite usualmente, com agressão à liberdade. Ao contrário, as pessoas se expõem livremente ao olho panóptico. Elas colaboram intensamente na edificação do panóptico digital na medida em que se desnudam e se expõem" (Han 2017, 115).

Diante desses paradoxos, Mejias, ${ }^{15}$ defende a necessidade de iniciar uma "descolonização dos grandes dados" por meio da negação da ideia de que a apropriação e utilização de dados obtidos de usuários da internet é um procedimento "natural e inevitável" na produção de conhecimento humano, quando na verdade é uma forma comercial de extração de dados movida por interesses econômicos e políticos.

\section{Contradições finais}

Segundo Góes, ${ }^{16}$ desde as revelações de Edward Snowden, quando o mundo ficou sabendo da promíscua relação entre o governo norte americano, através de suas agências de inteligência, e as grandes plataformas proprietárias, como Google, Facebook e Amazon, tem se falado à saciedade sobre dados, vigilância e controle social. No entanto, cada vez mais nos sentimos confortáveis em usar as "novidades tecnológicas" e ceder nossos dados para quem quiser obtê-los. Seja pelo analfabetismo midiático, inocência ou pelo simples fato de não ligarmos, continuamos a ceder os metadados de praticamente toda nossa ação digital. De fato, diz Costa, ${ }^{17}$ se o Facebook, ou outra qualquer rede social, nos pedir o consentimento para usar a nossa informação pessoal não só para fins publicitários, mas também para sondagens eleitorais, em troca do serviço de contato online com amigos e de acesso aos mecanismos de buscas, possivelmente iremos aceitar.

Em 20 de outubro de 2020, o Departamento de Justiça dos EUA e onze estados americanos entraram com uma ação contra o Google por concorrência desleal, alegando "operação casada" do seu mecanismo de busca nos contratos com os fabricantes de dispositivos móveis. O Google declarou em um tweet que a ação está profundamente equivocada, que os usuários usam o Google por escolha própria, e não porque são obrigados a fazê-lo ou porque não encontram alternativas. O argumento é em parte legítimo, no estrito senso é fato que não somos obrigados a pesquisar no Google nem ter perfil no Facebooke no Instagram, nem nos comunicar via WhatsApp. Por outro lado, é inegável a eficiência e o alcance dos serviços oferecidos por essas plataformas.

\footnotetext{
15 Mejias, Ulises. 2019. Questionando o universalismo por trás dos dados: entrevista com Ulises Mejias. Digilabour (blog), 13 dez. 2019 Acessado 10 de out. 2020. https://digilabour.com.br/2019/12/13/questionando-o-universalismo-por-tras-dos-dados-entrevista-com-uLises-mejias/

16 Góes, Victor. 2018. HYPERLINK "http://labcon.fafich.ufmg.br/datificacao-e-dataismo-para-alem-do-controle-social/"Datificação e Dataísmo: para além do controle social. Lab.Com (blog), 27 nov. 2018. Acessado 20 jan. 2020. http://labcon.fafich.ufmg.br/datificacao-e-dataismo-para-alem-do-controle-social/

17 Costa, Carlos. 2018. Dataísmo, a religião do século XXI. ClO (blog), 01 ago. 2018. Acessado 10 de nov. 2019. https://cio.com.br/tendencias/dataismo-a-religiao-do-seculo-xxi/
} 
Por isso mesmo, não estamos dispostos a pagar o custo de ficar fora dessa interconexão planetária e dos nossos mimosos smartphones que colocam o mundo na palma de nossas mãos.

O que tudo isso revela é que o fosso das contradições, paradoxos e ambivalências está se abrindo diante de nós como um abismo que traz de volta a velha pergunta: o que fazer? Certamente não existem respostas simples para questões arquicomplexas. De todo modo, não podemos nos furtar e entrar nas conversações em busca de brechas que possam iluminar o abismo. Para começar, parece claro que precisamos colocar os dedos nas feridas das contradições, repensar nossos arcabouços ontológicos, epistemológicos e éticos, estabelecer pontes entre os principios gerais e os procedimentos para os desenvolvedores e implementadores das novas tecnologias. Vivemos, paradoxalmente, estados de distopia e utopia, as mesmas tecnologias oferecem enormes beneficios e enormes ameaças. Essa é uma das fontes da arquicomplexidade do mundo e do modo como nos aparece neste penoso ano de 2020.

\section{Referências}

Bruno, Fernada. 2012. Rastros digitais sob a perspectiva da teoria ator-rede. Famecos 19 (3): 681-704. https:// doi.org/10.15448/1980-3729.2012.3.12893.

Couldry, Nick e Ulises Mejias. 2019. The costs of connection. How data is colonizing human life and appropriating it for capitalism. Palo Alto: Stanford University Press.

Freud, Sigmund. 2019. O infamiliar. São Paulo: Autêntica.

Frischmann, Brett e Evan Selinger. 2018. Re-engineering humanity. Cambridge: Cambridge University Press.

Han, Byung-Chul. 2019. Sociedade da transparência. Rio de Janeiro: Editora Vozes.

Harari, Yuval Noah. 2016. Homo Deus. Uma breve história do amanhã. São Paulo: Companhia das Letras.

Hoffmann, Ernst T. A. 2010. O homem da areia. Rio de Janeiro: Rocco Jovens Leitores.

Lohr, Steve. 2015. Data-ism. The Revolution transforming decision making, consumer behavior, and almost everything else. New York: Harper Business.

Mayer-Schonberger, Viktor e Kenneth Cukier. 2013. Big data: a revolution that will transform how we live, work, and think. New York: Houghton Mifflin Harcourt.
Mayer-Schonberger, Viktor e Thomas Ramge. 2018. Reinventing capitalism in the age of big data. London: John Murray.

O'Nel, Cathy. 2016. Weapons of math destruction: How big data increases inequality and threatens democracy. New York: Crown.

Poe, Edgar Allan. 1985. William Wilson. In Contos de Edgar Allan Poe, traduzido por José Paulo Paes, 109128. São Paulo: Cultrix.

Russell, Stuart. 2019. Human compatible: artificial intelligence and the problem of control. Londres: Penguin Books.

Santaella, Lúcia. 1985. Estudo Crítico: Edgar Allan Poe O que em mim sonhou está pensando. In Contos de Edgar Allan Poe, 139-189. São Paulo: Cultrix.

Santaella, Lucia e Mariane Cara. 2014. As performances subjetivas na espetacularização dos corpos. In Sociotramas. Estudos multitemáticos sobre redes digitais, organizado por Lucia Santaella, 77-90. Barueri: Estação das Letras e Cores.

Srnicek, Nick. 2017. Platform capitalism. London: Polity Press.

Van Dijck, José. 2017. Confiamos nos dados? As implicações da datificação para o monitoramento social. MATRIZes 11 (1): 39-59. https://doi.org/10.11606/ issn.1982-8160.v11i1p39-59.

Zuboff, Shoshana. 2019. The age of surveillance capitalism. The fight for a human future at the new frontier of power. London: Profile Books.

\section{Lucia Santaella}

Doutora em Teoria Literária pela Pontifícia Universidade Católica de São Paulo (PUC-SP), São Paulo, SP, Brasil; pós-doutorado na Gesamthochschule Kassel, U. K., Alemanha e pela Indiana University, IU Bloomington, Estados Unidos; professora da Pontifícia Universidade Católica de São Paulo (PUC-SP), São Paulo, SP, Brasil; livre docente da Universidade de São Paulo (USP), São Paulo, SP, Brasil.

\section{Dora Kaufman}

Doutora em Ciências da Comunicação pela Universidade de São Paulo (USP), São Paulo, SP, Brasil; pós- doutorado em Engenharia de Produção Universidade Federal do Rio de Janeiro (COPPE-UFRJ), no Rio de Janeiro, RJ, Brasil e em Tecnologias de Inteligência e Design Digital pela Pontifícia Universidade Católica de São Paulo (TIDD/ PUC-SP), São Paulo, Brasil; professora da Pontifícia Universidade Católica de São Paulo, São Paulo, SP, Brasil.

Os textos deste artigo foram revisados pela Poá Comunicação e submetidos para validação do autor antes da publicação. 